\title{
Wear behavior of copper-containing ferritic iron under a dry sliding condition"
}

\author{
Junaidi SYARIF ${ }^{\dagger}$, Agung ISWADI, Mariyam Jameelah GHAZALI, Zainuddin SAJURI, Mohd Zaidi OMAR \\ (Department of Mechanical and Materials Engineering, Faculty of Engineering and Built Environment, \\ Universiti Kebangsaan Malaysia, 43600 Bangi, Selangor, Malaysia) \\ †E-mail: syarif@eng.ukm.my; syarif.junaidi@gmail.com
}

Received June 18, 2013; Revision accepted Oct. 22, 2013; Crosschecked Nov. 14, 2013

\begin{abstract}
The effect of solute $\mathrm{Cu}$ and $\mathrm{Cu}$ precipitates on the wear behavior of ferritic iron under an unlubricated condition was investigated. The specific wear rate of $\mathrm{Cu}$-containing steel abruptly decreased up to $50 \mathrm{~N}$ of load, and then gradually decreased with further increased load. The specific wear rate of the as-quenched specimen, in which $\mathrm{Cu}$ was in a solid solution, was the lowest among all the specimens at low loads, and all specimens had almost the same specific wear rate at high loads. Subsurface observation showed that the hardness increments of all specimens decreased with increased depth below the worn surface. The as-quenched specimen had a relatively large depth of deformed region than the other specimens even though the increments in hardness were almost the same for all specimens at low loads. With the same hardness at an unworn state, the as-quenched and over-aged specimens exhibited a substantial increase in hardness and large deformed regions below the worn surfaces. This finding indicated that the enhancement in plastic deformation and work hardening led to the decrease in the specific wear rate of the as-quenched specimen at low loads and the improvement in the wear resistance of all specimens at high loads.
\end{abstract}

Key words: Steel, Hardness, Sliding wear, Work hardening, Plastic deformation

doi:10.1631/jzus.A1300211 Document code: A CLC number: TG16

\section{Introduction}

Many attempts have been made to utilize $\mathrm{Cu}$ as an alloying element in steels for engineering applications because of its ability to strengthen steels. For instance, Rana et al. (2007) and Ghosh et al. (2007) tried to utilize $\mathrm{Cu}$-precipitation in an interstitialfree (IF) steel and a microalloyed steel, respectively. Noro et al. (1997) reported that the use of $\mathrm{Cu}$ as an alloying element is also an effective method of promoting the recycling process of $\mathrm{Cu}$-contaminated steel scraps. Numerous studies such as Russell and Brown (1972) and Syarif et al. (2007) indicated that $\mathrm{Cu}$ can improve the mechanical properties of steels based on two mechanisms: precipitation strengthening, as well as solid solution strengthening. Both

\footnotetext{
* Project (No. UKM-KK-02-FRGS0012-2008) supported by the Ministry of Higher Education, Malaysia

(C) Zhejiang University and Springer-Verlag Berlin Heidelberg 2013
}

mechanisms can increase the yield strength of steels, although the former is more effective. Syarif et al. $(2000 ; 2003)$ also reported that $\mathrm{Cu}$ in solid solution can also decrease the ductile-to-brittle transition temperature of ferritic iron, increase the hardness of iron, and improve the strength of steel without diminishing its toughness.

Other researchers attempted to utilize $\mathrm{Cu}$ for wear-resistant applications such as rolling bearing, whose main requirements include high hardness. Accordingly, Hutchings (2001) explained that up to $1 \%$ (in weight) $\mathrm{C}$ is added to a rolling bearing material to increase its hardness. However, the toughness of a material may be lowered by increasing the $\mathrm{C}$ concentration. This problem can be solved using $\mathrm{Cu}$, which can increase the hardness of a rolling bearing material without increasing the $\mathrm{C}$ concentration, as well as improve the strength and toughness of the material simultaneously. 
In this study, the wear properties of $\mathrm{Cu}$ containing ferritic iron under a dry sliding condition were investigated to determine the influence of $\mathrm{Cu}$ addition on wear behavior of ferritic iron. The effects of solute $\mathrm{Cu}$ and its precipitates in the matrix on wear behavior were also examined in relation to the plastic deformation and work hardening behavior of the alloy.

\section{Experiments}

In this study, a $\mathrm{Fe}-3 \% \mathrm{Cu}$ (in weight) alloy was prepared as test specimens. The chemical composition is shown in Table 1. The ingot was produced under vacuum conditions using an induction furnace, and then hot rolled into a $25 \mathrm{~mm}$-thick plate at $1100 \mathrm{~K}$. The specimens were subjected to a solution treatment at $1273 \mathrm{~K}$ for $1.8 \mathrm{ks}$, followed by water quenching. The specimens were then aged at $873 \mathrm{~K}$ for $10 \mathrm{~s}$ to $18 \mathrm{ks}$ and water quenched. Microstructures were observed using an optical microscope for all specimens, which were chemically etched with $3 \%$ Nital. The hardness was represented by the average of five measurements in Vickers hardness testing under a normal load of $29.4 \mathrm{~N}$. The wear test was conducted using a pin-on-disc configuration under a dry sliding condition with five different loads: $19.6 \mathrm{~N}, 49.1 \mathrm{~N}$, $98.1 \mathrm{~N}, 147.2 \mathrm{~N}$, and $196.2 \mathrm{~N}$ (corresponding to initial normal stress of 1-10 $\mathrm{MPa}$ on the pin), at a fixed sliding speed of $1 \mathrm{~m} / \mathrm{s}$ at ambient temperature. For the wear test, the $\mathrm{Fe}-3 \% \mathrm{Cu}$ alloy and an EN-31 steel with a hardness of HV 698 were used as a pin and a counterface, respectively. The $\mathrm{Fe}-3 \% \mathrm{Cu}$ alloy was machined to cylindrical test pieces of $\Phi 5 \mathrm{~mm} \times 20 \mathrm{~mm}$ gauge dimension. The diameter of the wear track was set to be $40-120 \mathrm{~mm}$. The chemical composition of the EN-31 steel is also shown in Table 1. Prior to testing, all specimens were cleaned with acetone and weighed to an accuracy of $\pm 0.001 \mathrm{~g}$ at $1.8 \mathrm{ks}$ intervals during the test (corresponding to sliding distance of 1800-7200 mm). The volume loss was obtained by dividing the measured mass loss by the $\mathrm{Fe}-3 \% \mathrm{Cu}$ alloy density of $7.89 \mathrm{~g} / \mathrm{cm}^{3}$, which was calculated by JMatPro $^{\text {TM }}$ software. The worn surface was observed using an infinite focus microscope (Alicona), and then characterized using a scanning electron microscopy (SEM) system and an energy-dispersive X-ray spectroscopy instrument. The surface roughness $\left(R_{\mathrm{a}}\right)$ of the worn surface was measured by Alicona using a profile analysis method following the EN ISO 4287 standard. All worn specimens were nickel electroplated and sectioned parallel to the sliding direction for microstructural observations of the subsurface. The microstructures and hardness of the subsurface were observed and tested using an optical microscope and a microhardness tester, respectively. For comparison, a tensile test was conducted on the unworn specimen using an Instron universal tensile machine at an initial strain rate of $10^{-3} \mathrm{~s}^{-1}$ for plate specimens with the gauge length of $17 \mathrm{~mm}$.

Table 1 Chemical composition of steel used (\%, in weight) ${ }^{*}$

\begin{tabular}{|c|c|c|c|c|c|c|c|}
\hline Sample & $\mathrm{Cu}$ & $\mathrm{C}$ & $\mathrm{Si}$ & $\mathrm{Mn}$ & $\mathrm{Ni}$ & $\mathrm{Cr}$ & $\mathrm{Fe}$ \\
\hline $\mathrm{Fe}-3 \% \mathrm{Cu}$ & 2.98 & 0.007 & $<0.01$ & 0.007 & - & - & Bal. \\
\hline $\begin{array}{c}\text { EN-31 } \\
\text { steel }\end{array}$ & - & 1.00 & 0.28 & 0.31 & 0.21 & 1.71 & Bal. \\
\hline
\end{tabular}

\section{Results and discussion}

\subsection{Microstructures and hardness of $\mathrm{Fe}-3 \% \mathrm{Cu}$ alloy}

Fig. 1 shows the optical micrographs of the asquenched and aged $\mathrm{Fe}-3 \% \mathrm{Cu}$ alloy. No significant difference was observed between the two specimens. All specimens exhibited a massive ferritic structure and had almost the same grain size (around $100 \mu \mathrm{m}$ ). Nakashima et al. (2002) reported that $\mathrm{Cu}$ particles with sizes varying from $10 \mathrm{~nm}$ to $50 \mathrm{~nm}$ are finely dispersed within the matrix of aged $\mathrm{Fe}-3 \% \mathrm{Cu}$ alloys. Fig. 2 shows a change in the hardness of the specimen as a function of the aging time. According to (Syarif et al., 2003), the hardening mechanism of the asquenched specimen was attributed to the solid solution hardening of supersaturated $\mathrm{Cu}$ atoms within the ferritic matrix, which resulted from the massive austenite-to-ferrite transformation. The hardness of the aged specimens gradually increased from HV 180 to HV 300 at $200 \mathrm{~s}$ before they gradually decreased with increased aging time. These results were consistent with those of Nakashima et al. (2002). Hornbogen and Glenn (1960) also reported that the coherence between the body-centered cubic $\mathrm{Cu}$ particles and the ferritic matrix leads to an increase in hardness, whereas Nakashima et al. (2002) suggested that the decrease of the hardness of the over-aged specimen is 
influenced by the incoherence between the $\mathrm{Cu}$ particles and the matrix at the interface, which was also reported by Othen et al. (1994). Thus, the 6 ksaged specimen with a hardness of HV 201 was used as the over-aged specimen in this study because its hardness was almost the same with that of the as-quenched specimen with a hardness of HV 180.

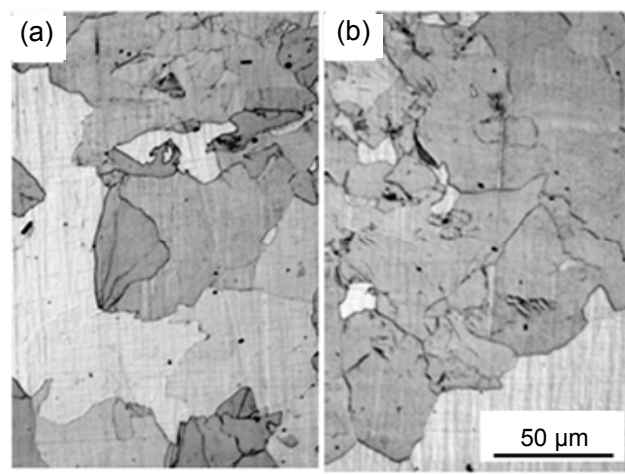

Fig. 1 Optical micrographs of the $\mathrm{Fe}-3 \% \mathrm{Cu}$ alloy: as-quenched (a) and 200 s-aged (b) specimens

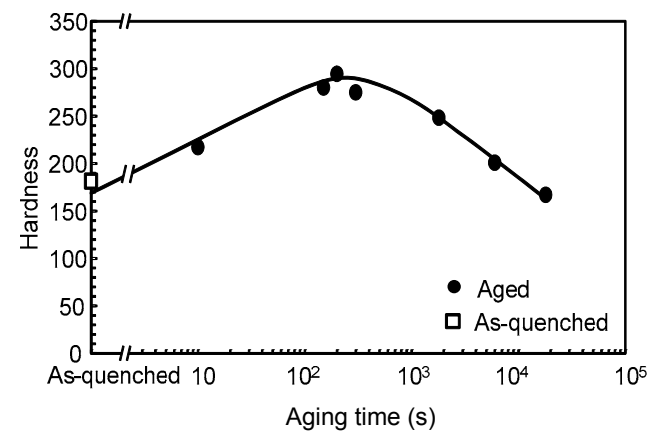

Fig. 2 Changes in hardness as a function of the aging time for $\mathrm{Fe}-3 \% \mathrm{Cu}$ alloy

\subsection{Wear behavior of $\mathrm{Fe}-3 \% \mathrm{Cu}$ alloy}

Gore and Gates (1997) showed that the wear resistance of steel strongly depends on its hardness, hence the wear resistance of ferritic iron can be improved by adding some $\mathrm{Cu}$ precipitates. Fig. 3 shows the relationship between the volume loss of all specimens and the sliding distances at various loads. The volume losses of all specimens increased with the increase of sliding distance. The volume loss of the over-aged specimen was higher than those of the other specimens, except at $98.1 \mathrm{~N}$ load and $7.2 \mathrm{~km}$ sliding distance. In the case of the applied loads, the volume loss increased with the increase of loads, with the as-quenched specimens exhibiting good wear resistance at both low and high loads.
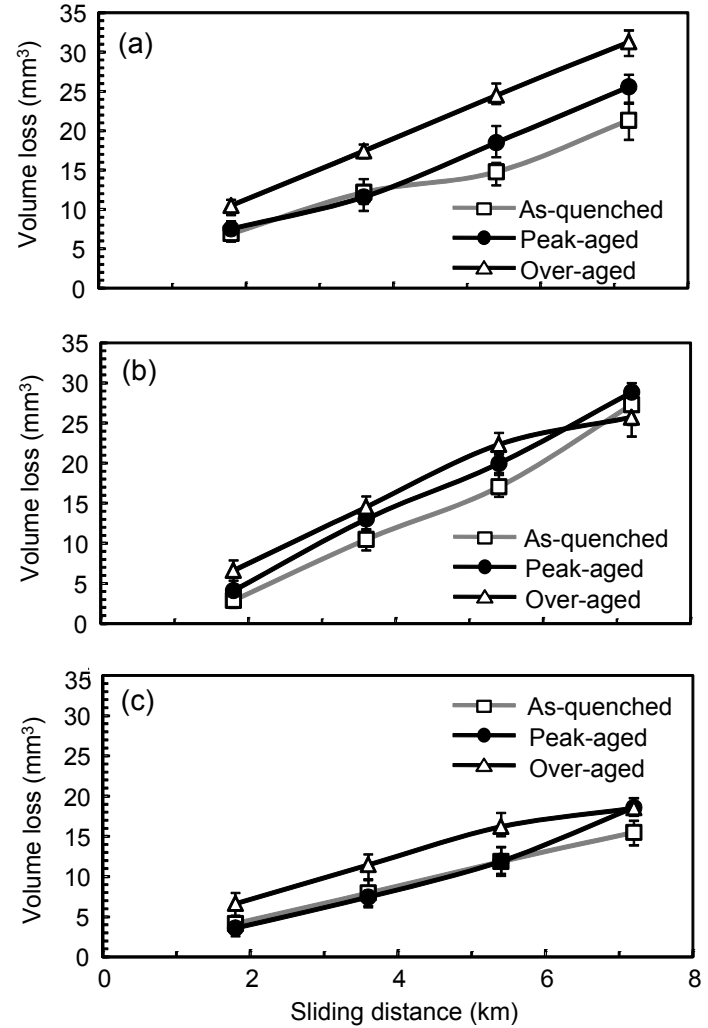

Fig. 3 Relationship between volume loss of all specimens and sliding distance at various loads of $196.2 \mathrm{~N}$ (a), 98.1 N (b), and 19.6 N (c)

Lancaster (1967) and Archard (1953) proposed the specific wear rate $k_{2}$ and the wear rate $k^{\prime}$, respectively in relation with the volume loss $\Delta V$ governed by the following equations:

$$
\begin{aligned}
& \Delta V=k_{2} P L, \\
& \Delta V=k^{\prime} P L / \mathrm{HV},
\end{aligned}
$$

where $P$ is the load, $L$ is the sliding distance, and HV is the Vickers hardness of the softer material. The volume loss is then obtained as

$$
\Delta V=\Delta m / \rho,
$$

where $\Delta m$ is the mass loss and $\rho$ is the density of $\mathrm{Fe}-3 \% \mathrm{Cu}$ alloy $\left(7.89 \mathrm{~g} / \mathrm{cm}^{3}\right)$. The changes in the specific wear rates of all specimens in relation to the load are shown in Fig. 4. The specific wear rates at a sliding distance of $7.2 \mathrm{~km}$ were calculated. The rates abruptly decreased up to $50 \mathrm{~N}$ of applied load, and then gradually decreased with further increased load. 
Overall, the specific wear rates indicated that all specimens possessed good wear resistance at high loads. The specific wear rates of the as-quenched specimens ranged from $1.5 \times 10^{-5} \mathrm{~mm}^{3} /(\mathrm{N} \cdot \mathrm{m})$ to $10.9 \times 10^{-5} \mathrm{~mm}^{3} /(\mathrm{N} \cdot \mathrm{m})$, whereas those of the peakand over-aged specimens ranged from $1.8 \times 10^{-5}$ $\mathrm{mm}^{3} /(\mathrm{N} \cdot \mathrm{m})$ to $13.2 \times 10^{-5} \mathrm{~mm}^{3} /(\mathrm{N} \cdot \mathrm{m})$ and from $2.2 \times 10^{-5} \mathrm{~mm}^{3} /(\mathrm{N} \cdot \mathrm{m})$ to $13.1 \times 10^{-5} \mathrm{~mm}^{3} /(\mathrm{N} \cdot \mathrm{m})$, respectively. In accordance with the specific wear rates for carbon steel found by Goto and Amamoto (2011), the $k_{2}$ values indicated that the wear of the $\mathrm{Fe}-3 \% \mathrm{Cu}$ alloys were within the severe-wear regime. Given that the $k_{2}$ values of the as-quenched specimens were smaller than those of the peak- and over-aged specimens at almost all loads, the as-quenched specimen exhibited better wear resistance than the other specimens.

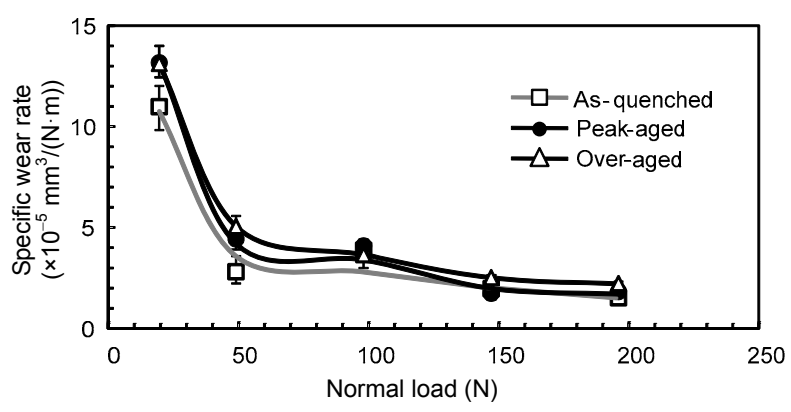

Fig. 4 Changes in the specific wear rates of all specimens as a function of load at a sliding distance of $7.2 \mathrm{~km}$

Several investigations have been conducted to explain the wear mechanism in steels. Gore and Gates (1997), as well as Bressan et al. (2008) reported that the wear mechanism and wear rate of steels are strongly related to the hardness of the material. Gore and Gates (1997) reported that an increase in hardness improves the wear resistance. A mild steel with a hardness of HV 136 shows higher volume loss than a hardenable steel with a hardness of HV 279. On the other hand, Sundström et al. (2001) reported that the correlation between the mass loss and hardness of steel is incompatible, suggesting that the wear resistance of steel should be attributed to the change in the hardness of the worn subsurface area. The wear tests showed that the specific wear rate of the as-quenched specimen was better than those of the other specimens. However, the as-quenched specimen showed the lowest hardness. Therefore, our findings agreed very well with those of Sundström et al. (2001).

\subsection{Surface morphology of worn specimens}

To verify the effect of $\mathrm{Cu}$ addition on the wear resistance of ferritic iron, the morphologies and microstructures of the worn surfaces and subsurfaces of all specimens were observed, respectively. Fig. 5 shows the SEM images of all worn surfaces of specimens (pin) and their corresponding average roughness $\left(R_{\mathrm{a}}\right)$. All specimens were tested at various loads for a $7.2 \mathrm{~km}$ sliding distance. The typical surface damage of worn metallic materials, such as ploughing and delamination, was observed and is marked by arrows. The severity of the worn surface increased with the increase of load up to $98.1 \mathrm{~N}$, then it decreased up to the highest load (196.2 N).

The over-aged specimen suffered the highest wear at all loads. Meanwhile, the severity of the worn surface of the as-quenched specimen was far more remarkable than that of the peak-aged specimen, particularly at $19.6 \mathrm{~N}$, although $k_{2}$ of the former was smaller than that of the latter. On the other hand, at the highest load $(196.2 \mathrm{~N})$, the trend was somehow reversed; the wear severity of the peak-aged specimens was more remarkable than that of the as-quenched specimens. This result indicates that the wear mechanism was altered by an increasing load. Farrell and Eyre (1970) and Eyre and Maynard (1971) reported that when various steels are subjected to the wear test, transition from mild to severe wear effects occurs within a certain load range. The worn surface observation in the present study agreed very well with that of Rai et al. (2007). They discovered that Ni-Cr-Mo-V steels suffered mild/oxidative wear at low loads, which became more severe with the increase of load. Indeed, delamination wear was observed at low loads and oxidative wear was observed at high loads. In general, the over-aged specimen showed the highest $k_{2}$ and $R_{\mathrm{a}}$ among all specimens. Hence, a strong relationship existed between $k_{2}$ and $R_{\mathrm{a}}$.

\subsection{Subsurface observation and work hardening of $\mathrm{Fe}-3 \% \mathrm{Cu}$ alloy}

Sundström et al. (2001) reported that the change in the subsurface hardness of a worn specimen can be explained by the wear behavior of steels. Thus, the microstructure and hardness of the subsurfaces were investigated to clarify the effect of $\mathrm{Cu}$ on the wear behavior. Fig. 6 shows the subsurface microstructure 

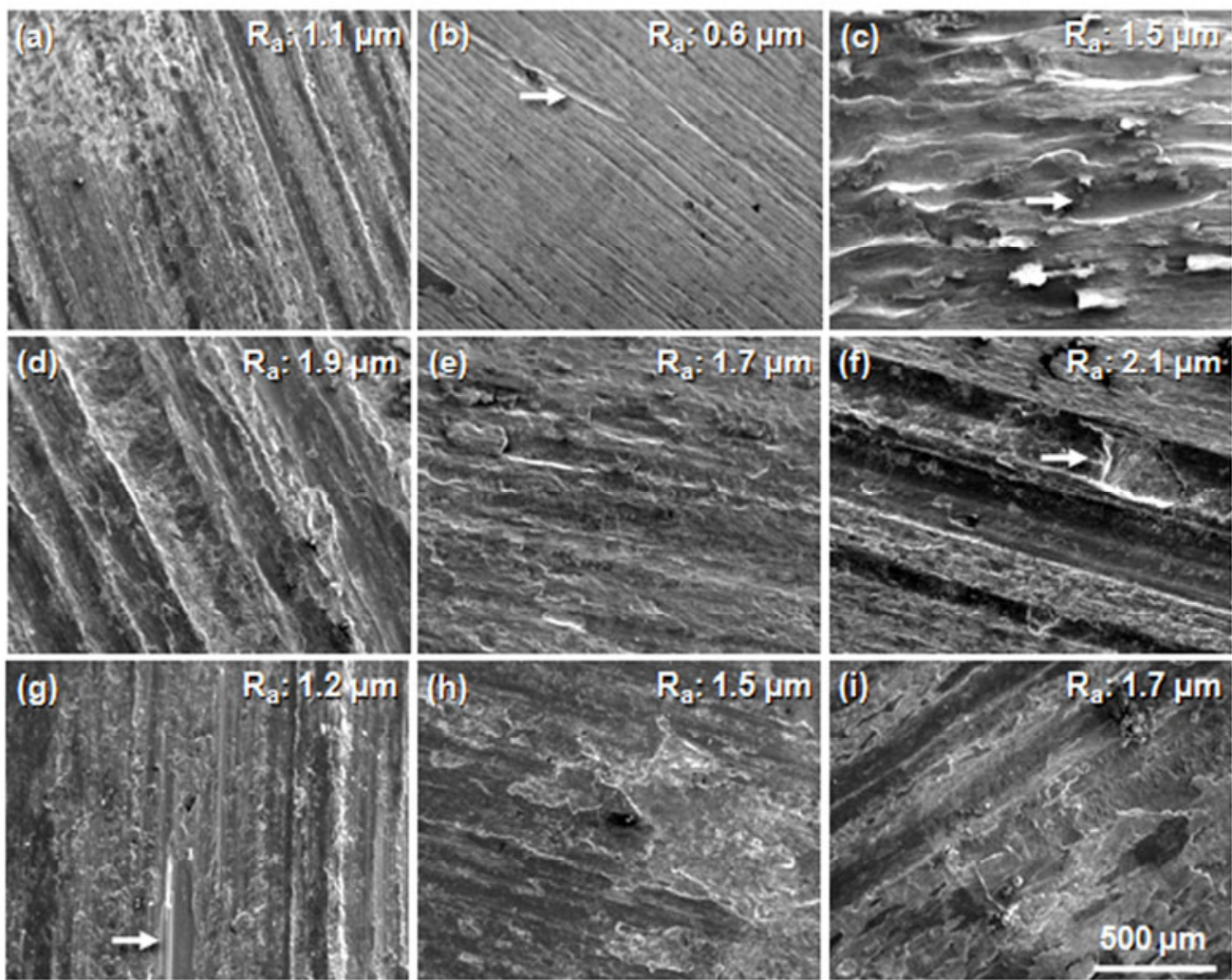

Fig. 5 SEM micrographs of all specimens' worn surfaces after wear tests for a $\mathbf{7 . 2} \mathbf{~ k m}$ sliding distance (a) As-quenched at $19.6 \mathrm{~N}$; (b) Peak-aged at $19.6 \mathrm{~N}$; (c) Over-aged at $19.6 \mathrm{~N}$; (d) As-quenched at $98.1 \mathrm{~N}$; (e) Peak-aged at 91.8 N; (f) Over-aged at 98.1 N; (g) As-quenched at 196. 2 N; (h) Peak-aged at 196.2 N; (i) Over-aged at 196.2 N

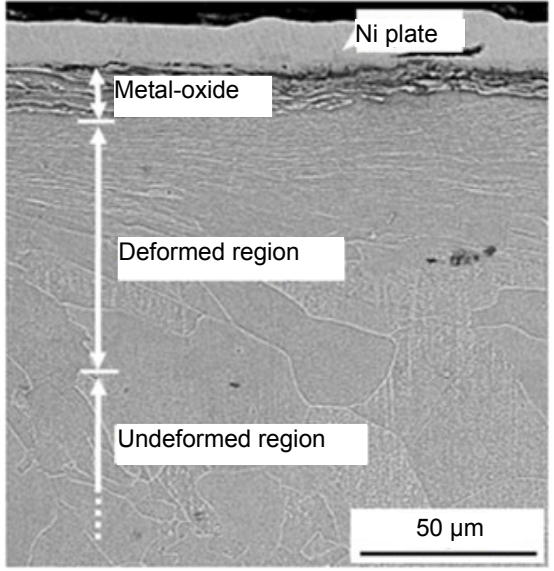

Fig. 6 Subsurface microstructure of a peak-aged specimen at $98.1 \mathrm{~N}$ load and $7.2 \mathrm{~km}$ sliding distance

of a peak-aged specimen at $98.1 \mathrm{~N}$ and $7.2 \mathrm{~km}$ of sliding distance. According to Gui et al. (2000), the subsurface microstructure consisted of three distinguished zones, namely, undeformed, deformed, and metal-oxide (or mechanically mixed layer) regions. The plastically deformed region exhibited elongated grains that distorted toward the sliding direction of the counterface.

Fig. 7 shows the change in hardness as a function of depth below the worn surface at 19.6, 98.1, and $196.2 \mathrm{~N}$. The hardness of the worn specimen was higher than that of the unworn specimen with increased load. For instance, the hardness of the asquenched specimen increased almost 1.8 fold after a wear test at $196.2 \mathrm{~N}$. These results agreed very well with Hirst and Lancaster (1960). For all specimens, the hardness decreased with the increase of depth below the worn surface, and the depths of the deformed region increased with the increase of load. The dashed lines in Fig. 7 show the hardness of the asheated specimen (unworn specimen) and indicate the undeformed region.

The peak-aged specimen had the highest hardness at all loads, but the as-quenched and over-aged specimens possessed similar hardness values with the deformed region. Furthermore, the as-quenched specimens had the largest deformed region; its depth 
increased to $500 \mu \mathrm{m}$ at the highest load. Although the peak-aged specimen had the highest hardness in the undeformed region, the as-quenched and over-aged specimens had a very high increase in hardness in both deformed and undeformed regions, with values of HV 151 and HV 161, respectively. This finding suggested that the as-quenched and over-aged specimens had experienced tremendous plastic deformation and work hardening.
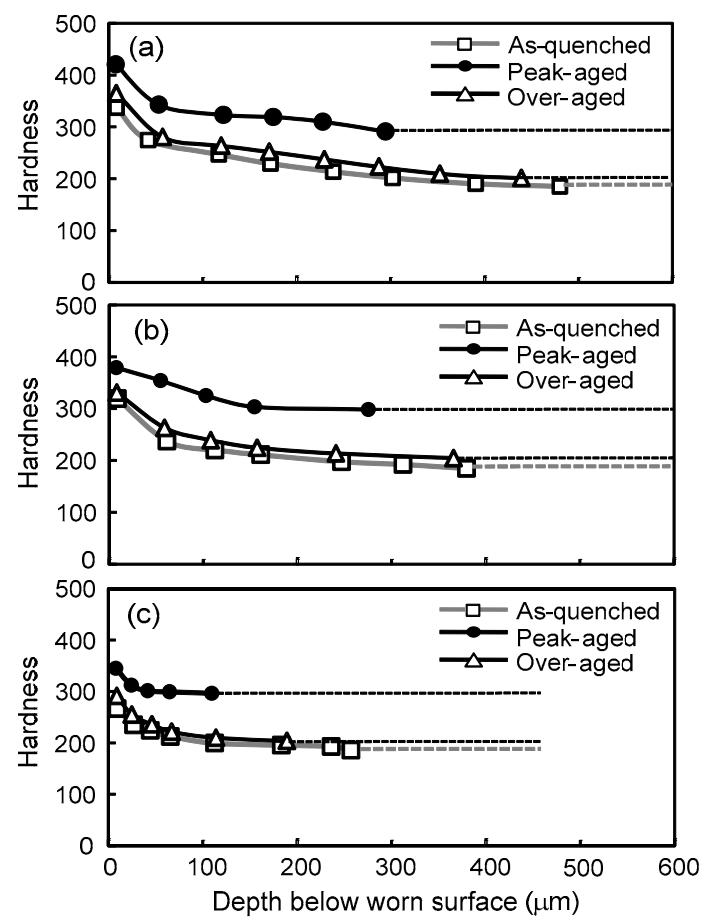

Fig. 7 Changes in hardness as a function of depth below the worn surface at 196.2 N (a), 98.1 N (b), and $19.6 \mathrm{~N}$ (c)

To understand work hardening and plastic deformation behavior caused by wear, the relationship between $\Delta \mathrm{HV}_{\max }$ and $\Delta d_{\max }$ for all specimens is plotted in Fig. 8. $\Delta \mathrm{HV}_{\max }$ was obtained from the hardness difference between the undeformed regions from the highest hardness underneath the worn surface, whereas $\Delta d_{\max }$ was obtained by subtracting the depth of the highest hardness beneath the worn surface from the depth of the undeformed region. $\Delta \mathrm{HV}_{\max }$ and $\Delta d_{\max }$ were then linearly related. The plots were also divided into three groups, namely, low, middle, and high $\Delta \mathrm{HV}_{\max }-\Delta d_{\max }$ for all three types of specimens at different loads. An increase in load led to a low-tohigh shift of the group, in which the increase in load simultaneously enhanced the plastic deformation and wear resistance. These results showed that the as- quenched specimens exhibited greater plastic deformation and work hardening than the other specimens. To evaluate the effect of plastic deformation and work hardening on wear behavior, the increase in hardness below the worn surface $(\Delta \mathrm{HV})$ was determined as

$$
\Delta \mathrm{HV}=\mathrm{HV}-\mathrm{HV}_{\mathrm{o}},
$$

where $\mathrm{HV}$ and $\mathrm{HV}_{\mathrm{o}}$ are the hardness values of the deformed and undeformed regions, respectively. The data from Fig. 4 were used in the calculation. Syarif et al. (2000) and Busby et al. (2005) reported that the tensile stress (MPa) and hardness (HV) have an empirical relationship, i.e., the stress $\sigma(\mathrm{MPa}) \approx 3 \mathrm{HV}$. Thus, the increment of hardness can be converted to stress with the following equation:

$$
\Delta \sigma(\mathrm{MPa}) \approx 3 \Delta \mathrm{HV} .
$$

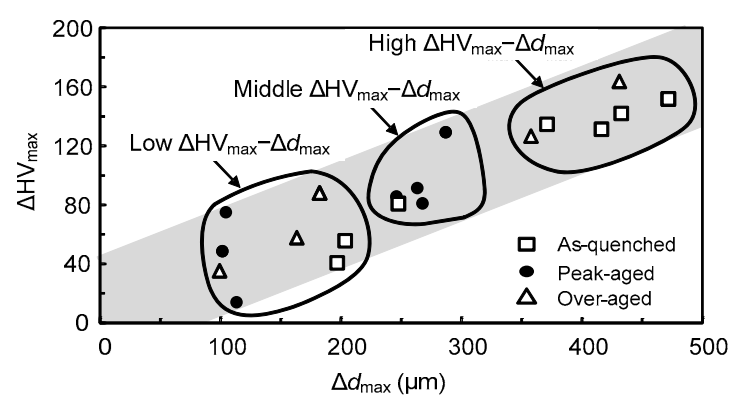

Fig. 8 Relationship between $\Delta H V_{\max }$ and $\Delta d_{\max }$ of all specimens

Fig. 9 shows the relationship between the increase in stress $\Delta \sigma$ and the depth of the deformed region below the worn surfaces for all specimens. At $19.6 \mathrm{~N}$, the slope of the as-quenched specimen was found to be the least steep among all other specimens, despite the similar stress values beneath the worn surface. Hence, the depth of the deformed region of the as-quenched specimen was also higher than those of the other specimens, indicating that plastic deformation and work hardening were more pronounced in the as-quenched specimen. With increased load, the changes in the stress increase in the peak- and over-aged specimens became more gradual, and the slopes were mostly the same as the slope of the as-quenched specimen. Although the depth of the deformed region for the peak-aged specimen was smaller, the plastic deformation and the work hardening behaviors of all specimens were almost the 
same at high loads. Fig. 10 shows the relationship between the specific wear rate and the depth of the deformation region below the worn surfaces for all specimens. The specific wear rate decreased as the depth of the deformed region increased for all specimens including the depth of the deformed region of the peak-aged specimen. It is indicative that the plastic deformation and the work hardening had a great influence on the decrease of the specific wear rate.

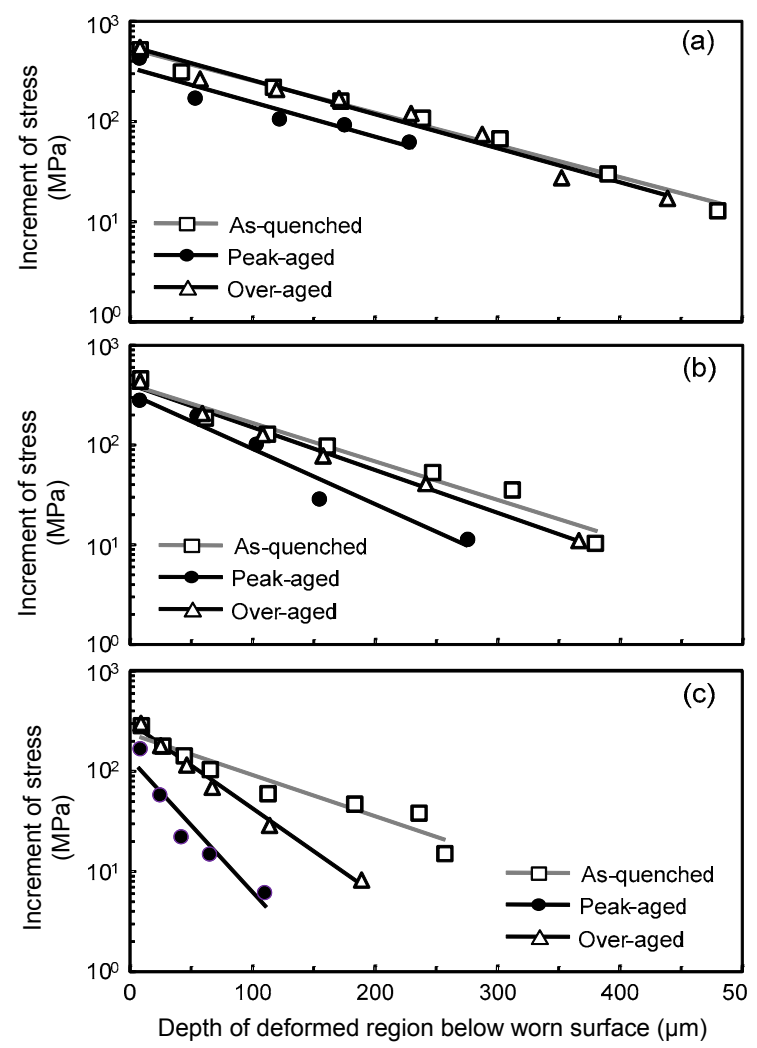

Fig. 9 Relationship between the increment of stress $\Delta \sigma$ and the depth of the deformed region below the worn surface for all specimens. All specimens were subjected to wear test for a sliding distance of $\mathbf{7 . 2} \mathbf{~ k m}$

(a) $196.2 \mathrm{~N}$; (b) $98.1 \mathrm{~N}$; (c) $19.6 \mathrm{~N}$

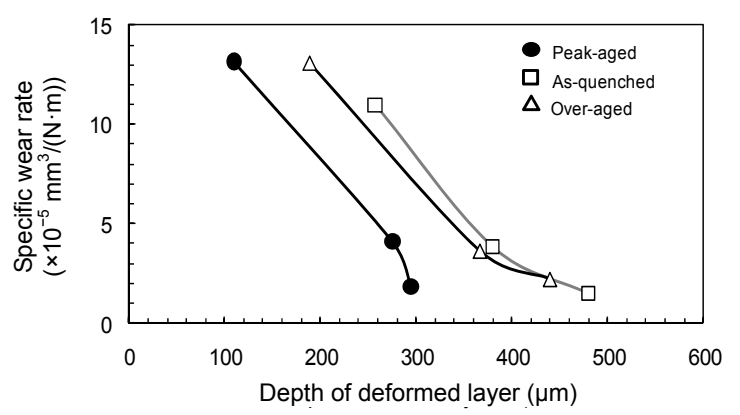

Fig. 10 Relationship between the specific wear rate and the depth of the deformation region below the worn surfaces for all specimens

\subsection{Correlation between wear behavior and tensile strength}

Chan et al. (2007) suggested that the wear behaviors of the metallic materials were strongly influenced by their tensile properties in general. Oh and Yeon (1998) noticed that the average wear amount abruptly increases with a decreased stress-strain (SS) ratio $\left(\phi_{\mathrm{u}}\right)$ at the ultimate point. The wear resistance increases with decreased sample ductility and increased ultimate tensile stress. In the present study, to measure the relationship between the wear behavior and tensile properties of $\mathrm{Fe}-3 \% \mathrm{Cu}$ alloys, several tensile tests were carried out. Fig. 11a shows the SS curves of the $\mathrm{Fe}-3 \% \mathrm{Cu}$ alloys. Notably, the peak-aged specimen possessed the highest yield stress of $613 \mathrm{MPa}$. However, its strain was the lowest among all specimens. Fig. 11b shows the relationship between the increment in stress $\Delta \sigma_{\text {tensile }}$ and the strain for all specimens. $\Delta \sigma_{\text {tensile, }}$ which corresponded to the work hardening, was calculated as follows:

$$
\Delta \sigma_{\text {tensile }}=\sigma-\sigma_{0.2 \%} \text {, }
$$

where $\sigma_{0.2 \%}$ is the $0.2 \%$ proof stress and $\sigma$ is the stress in a plastic region from the SS curve. $\Delta \sigma_{\text {tensile }}$ was calculated in the plastic deformation region in yielding to the ultimate tensile stress. An increase in the stress values of the as-quenched and peak-aged specimens was found to be approximately the same,
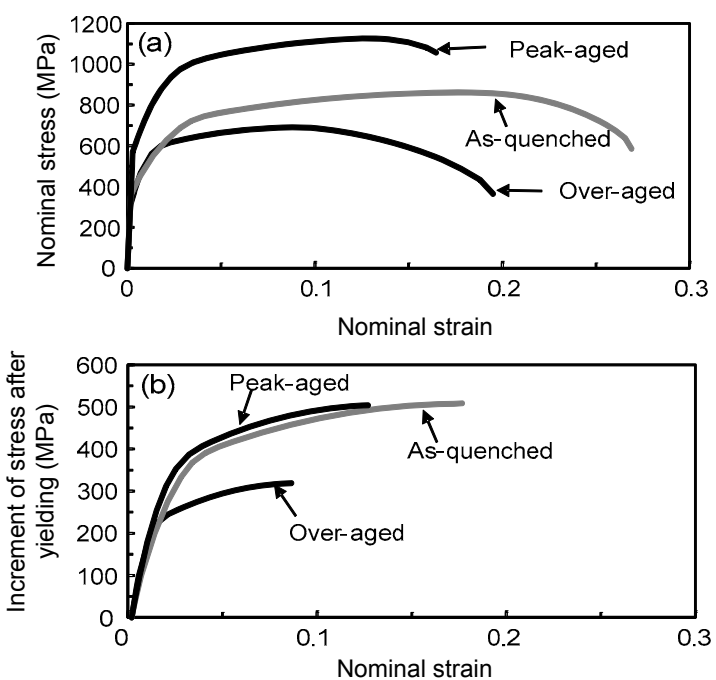

Fig. 11 Tensile properties of all specimens (a) Nominal stress-strain curves of all specimens; (b) Relationship between $\Delta \sigma_{\text {tensile }}$ and strain 
particularly at a strain of 0.127 , where $\Delta \sigma_{\text {tensile }}$ was around $504 \mathrm{MPa}$ for both specimens. As for the overaged specimens, they showed the smallest change in $\Delta \sigma_{\text {tensile }}$ among all as-quenched and peak-aged specimens. This result differed from the result shown in Fig. 9, in which all specimens showed the same stress increase caused by the wear test. For instance, the $\Delta \sigma$ values of all specimens were around $545 \mathrm{MPa}$ at $196.2 \mathrm{~N}$, and the $\phi_{\mathrm{u}}$ values of the as-quenched, peak-, and over-aged specimens were found to be 506.6, 924.5 , and $833.1 \mathrm{kgf} / \mathrm{mm}^{2}\left(1 \mathrm{kgf} / \mathrm{mm}^{2}=9.8 \mathrm{~N} / \mathrm{mm}^{2}\right)$, respectively. Although $\phi_{\mathrm{u}}$ of the peak-aged and as-quenched specimens showed the highest and lowest values, respectively, the current findings somehow differed from those of Oh and Yeon (1998). They likely used carbon steel specimens with the presence of the hard second phase such as pearlite or cementite, resulting in a significant work hardening effect compared with dispersed $\varepsilon$-Cu particles.

Despite having the lowest $\phi_{\mathrm{u}}$, the as-quenched specimens possessed the lowest specific wear rate among all other specimens. This result suggests that the wear behavior was not only influenced by the increase in ultimate tensile stress because of work hardening. The as-quenched and over-aged specimens exhibited relatively high elongation despite the occurrence of necking during the test. Dowling (2007) and Ling (1996) reported that work hardening occurs narrowly in the necked part of a tensile specimen after the necking stage. Thus, the fractured specimens from the tensile test were sectioned from the fractured surface area, and their hardness was measured to evaluate the work hardening of all specimens after the necking stage. Fig. 12 shows the relationship between the hardness and depth below the fractured surface area for all specimens. The hardness was found to decrease with increased depth, and then became constant. The constant hardness within the specimen indicated that the region experienced uniform elongation, whereas the increase in the hardness implied that the work hardening had occurred during the necking stage. An increase in the hardness of the over-aged and as-quenched specimens showed a similar trend (Fig. 7). This result indicated that the specific wear rate of the as-quenched specimen decreased at low loads because of the enhancement of plastic deformation and work hardening within the specimen. Therefore, the promotion of plastic deformation and work hardening also led to the decrease in the specific wear rates of all specimens at high loads, despite an initial low hardness value of the unworn as-quenched and over-aged specimens.

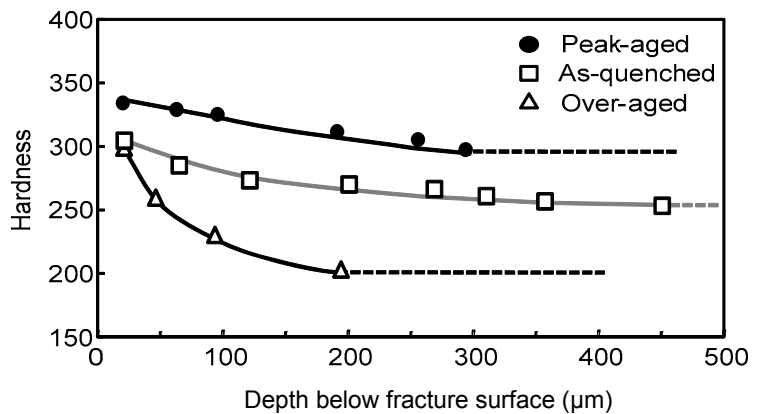

Fig. 12 Relationship between the hardness and depth below the fractured surface for all specimens

The above results indicate that the wear resistance of steel with high ductility not only depends on the hardness and ultimate tensile strength, but also on the plastic deformation and work hardening during the elongation and necking stages.

\section{Conclusions}

1. The hardness of the peak-aged specimen was found to be higher than that of the as-quenched specimen because of the precipitation hardening of $\mathrm{Cu}$ particles. The specific wear rates of all specimens abruptly decreased at $50 \mathrm{~N}$ load and gradually decreased with increased load. The specific wear rate of the as-quenched specimen was found to be the lowest at low loads, but then became similar to those of the other specimens at high loads.

2. The transition in the wear mechanism from mild to severe was most likely due to the increase in load. Subsurface observation showed that the asquenched and over-aged specimens had high hardness and large deformed regions below their worn surfaces.

3. The decrease in the specific wear rate of the as-quenched specimen at low loads was caused by the enhancement in plastic deformation and work hardening. The formation of the plastic deformation that enhanced the work hardening led to improved wear resistance of all specimens at high loads. 


\section{References}

Archard, J.F., 1953. Contact and rubbing of flat surfaces. Journal of Applied Physics, 24(8):981-988. [doi:10.1063/ 1.1721448]

Bressan, J.D., Daros, D.P., Sokolowski, A., Mesquita, R.A., Barbosa, C.A., 2008. Influence of hardness on the wear resistance of 17-4 $\mathrm{PH}$ stainless steel evaluated by the pin-on-disc testing. Journal of Materials Processing Technology, 205(1-3):353-359. [doi:10.1016/j.jmatprotec. 2007.11.251]

Busby, J.T., Hash, M.C., Was, G.S., 2005. The relationship between hardness and yield stress in irradiated austenitic and ferritic steels. Journal of Nuclear Materials, 336(2-3):267-278. [doi:10.1016/j.jnucmat.2004.09.024]

Chan, K.S., Koike, M., Okabe T., 2007. Modeling wear of cast Ti alloys. Acta Biomaterialia, 3(3):383-389. [doi:10. 1016/j.actbio.2006.10.007]

Dowling, N.E., 2007. Mechanical Behavior of Materials (3rd Edition). Pearson Prentice Hall, New Jersey, p.126-133.

Eyre, T.S., Maynard, D., 1971. Surface aspects of unlubricated metal-to-metal wear. Wear, 18(4):301-310. [doi:10.1016/ 0043-1648(71)90073-1]

Farrell, R.M., Eyre, T.S., 1970. The relationship between load and sliding distance in the initiation of mild wear in steels. Wear, 15(5):359-372. [doi:10.1016/0043-1648(70)90180-8]

Ghosh, S.K, Haldar, A., Chattopadhyay, P.P., 2007. Mechanical properties of directly air cooled copper added microalloyed steels. Materials Science and Technology, 23(11):1375-1380. [doi:10.1179/174328407X239046]

Gore, G.J., Gates, J.D., 1997. Effect of hardness on three very different forms of wear. Wear, 203-204:544-563. [doi:10. 1016/S0043-1648(96)07414-5]

Goto, H., Amamoto, Y., 2011. Improvement of wear resistance for carbon steel under unlubricated sliding and variable loading conditions. Wear, 270(11-12):725-736. [doi:10. 1016/j.wear.2010.12.010]

Gui, M.C., Kang, S.B., Lee, J.M., 2000. Wear of spray deposited Al-6Cu-Mn alloy under dry sliding conditions. Wear, 240(1-2):186-198. [doi:10.1016/S0043-1648(00)00354-9]

Hirst, W., Lancaster, J.K., 1960. The influence of speed on metallic wear. Proceedings of the Royal Society of London. Series A: Mathematical, Physical and Engineering Sciences, 259(1297):228-241. [doi:10.1098/rspa.1960.0220]

Hornbogen, E., Glenn, R.C., 1960. A metallographic study of precipitation of copper from alpha iron. Transactions of the Metallurgical Society of AIME, 218(6):1064-1070.

Hutchings, I.M., 2001. Tribology, Friction and Wear of Engineering Materials. Butterworth-Heinemann, Oxford, p.241-247.
Lancaster, J.K., 1967. The influence of substrate hardness on the formation and endurance of molybdenum disulphide films. Wear, 10(2):103-117. [doi:10.1016/0043-1648(67) 90082-8]

Ling, Y., 1996. Uniaxial True Stress-strain after Necking. AMP Journal of Technology, 5:37-48.

Nakashima, K., Futamura, Y., Tsuchiyama, T., Takaki, S., 2002. Interaction between dislocation and copper particles in $\mathrm{Fe}-\mathrm{Cu}$ alloys. ISIJ International, 42(12):15411545. [doi:10.2355/isijinternational.42.1541]

Noro, K., Takeuchi, M., Mizukami, Y., 1997. Necessity of scrap reclamation technologies and present conditions of technical development. ISIJ International, 37(3): 198-206. [doi:10.2355/isijinternational.37.198]

Oh, H.K., Yeon, K.H., 1998. Uniaxial tensile test and wear in metals. Journal of Materials Processing Technology, 79(1-3):113-124. [doi:10.1016/S0924-0136(97)00489-5]

Othen, P.J., Jenkins, M.L., Smith, G.D.W., 1994. Highresolution electron microscopy studies of the structure of $\mathrm{Cu}$ precipitates in $\alpha$-Fe. Philosophical Magazine A, 70(1):1-24. [doi:10.1080/01418619408242533]

Rai, D., Singh, B., Singh, J., 2007. Characterisation of wear behaviour of different microstructures in Ni-Cr-Mo-V steel. Wear, 263(1-6):821-829. [doi:10.1016/j.wear.2006. 12.014]

Rana, R., Bleck, W., Singh, S.B., Mohanty, O.N., 2007. Development of high strength interstitial free steel by copper precipitation hardening. Materials Letters, 61(14-15): 2919-2922. [doi:10.1016/j.matlet.2006.10.037]

Russell, K.C., Brown, L.M., 1972. A dispersion strengthening model based on differing elastic moduli applied to the iron-copper system. Acta Metallurgica, 20(7):969-974. [doi:10.1016/0001-6160(72)90091-0]

Sundström, A., Rendón, J., Olsson, M., 2001. Wear behaviour of some low alloyed steels under combined impact/ abrasion contact conditions. Wear, 250(1-12):744-754. [doi:10.1016/S0043-1648(01)00712-8]

Syarif, J., Hoshino, T., Tsuchiyama, T., Takaki, S., 2000. Effect of solute copper on hardness and ductile-to-brittle transition in $\alpha$-iron. Tetsu-to-Hagané, 86(8):558-562 (in Japanese).

Syarif, J., Tsuchiyama, T., Takaki, S., 2003. Mechanism of toughening in ferritic iron by solute copper at low temperature. ISIJ International, 43(7):1100-1104. [doi:10. 2355/isijinternational.43.1100]

Syarif, J., Nakashima, K., Tsuchiyama, T., Takaki, S., 2007. Effect of solute copper on yield strength in dislocationstrengthened steels. ISIJ International, 47(2):340-345. [doi:10.2355/isijinternational.47.340] 